\title{
Analysis Revelation of Successful Animation of Confucius on the domestic cartoon theme creation
}

\author{
LAI Weifan \\ Arts and Media College \\ China University of Geosciences \\ Wuhan, China \\ e-mail: houxw3000@163.com
}

\begin{abstract}
As late Spring and Autumn Confucius thinker, educator and statesman, founder of Confucianism . Arguably one of the representatives of the ancient Chinese philosophy , and in the international community also has a considerable reputation , and the animated film " Confucius " is the world's first two-dimensional images and animations in the form of the classic story about the twists and turns of Confucius upbringing, but also demonstrates the Confucian culture from among the lengthy process of formation of domestic animation. His creator not only respected historical authenticity, but also make it more interesting and full of thoughtful , so that China 's traditional Confucian culture of the more profound contemporary youth well accepted and very unique Chinese style, and education meaning. For this was a great success in the international arena, but also to become a classic of domestic animation .
\end{abstract}

Keywords-Confucius ;animated themes; revelation;domestic cartoon theme creation

\section{INTRODUCTION}

By the Publicity Department of the CPC Shandong Provincial Committee , China Confucius Foundation , Radio, Film and Television Bureau of Shandong Province, Shenzhen City Zonta Television Media Co., Ltd. coproduced animated film "Confucius" ( see Figure 1.1 ), this cartoon is about Confucius from a poor boy growing inspirational story of Jesus Christ Biao , Confucius were portrayed teenager, youth, the elderly are three stages of life . The film investment of nearly 50 million yuan, the production lasted three years, this has also enabled a powerful creative team behind the scenes ! General Counsel of the Great Masters Ji who had served as animation and personally wrote the title . Front half of the screenplay mainly by Zhang Yimou Queen "Gold screenwriter " Li Feng is responsible, the latter half penned by renowned writer Ye Zhaoyan, and finally by the Shandong Provincial Writers Association President Zhang Wei co-ordinate the whole draft, and fill in the cartoon theme song , " I am your fragrance "and" forever remembered . " CCTV host Liu Chunyan as a cartoon dubbing director, the film is still Confucius " confidante " Orchid dubbing. Descendants of Confucius, the famous musician Kong Xiangdong was composing cartoon, country artist Fan Zeng in cartoon character design also gives a lot of guidance. Animated film " Confucius" art production team is quite strong, the crew specially invited as a figure painter Mr. Dai Duibang design consultant , and set a number of senior animation designer.
To show a new image of Confucius . Literary image of the flesh and blood, breaking the previous stereotype people on Chinese culture and the inertia of the rigid way of thinking . Also for young people to establish a correct outlook on life and values have a good guide.

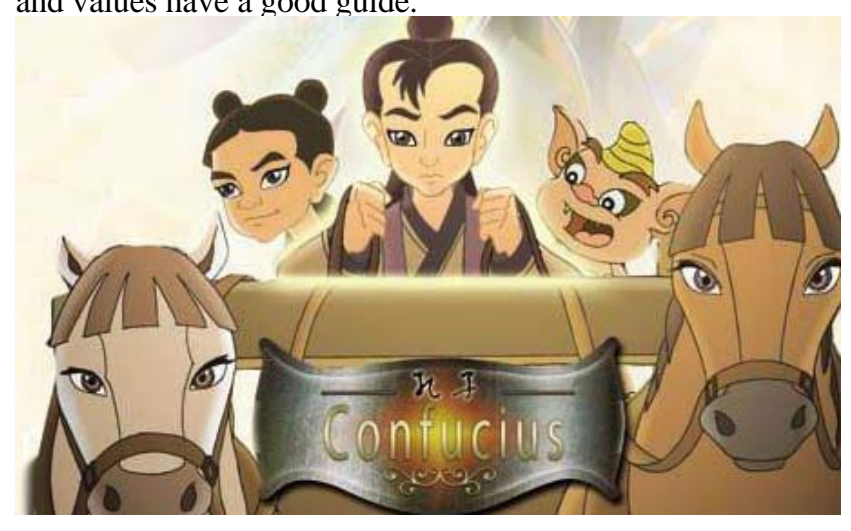

Figure 1. Confucius's cartoon.

\section{THE PRINCIPLE OF THE CREATION OF CONFUCIUS}

"Confucius" four broadcast season (26 episodes per quarter ), since September 28, 2009 be premiered in a CCTV widespread concern in the community, and won several national awards . In April 2010 , just aired only half of "Confucius " that the State Administration of Radio, cartoon recommended list of outstanding domestic first ; November 2010 in Guangdong Province won the 2005-2010 Pokka Television Arts Award . Animated film " Confucius" is also favored by the overseas market . In addition to more than 60 domestic provinces and cities in a joint television broadcast, the film smoothly into South Korea in late 2010 , successfully boarded the overseas screen . In early April this year , "Confucius" expedition will be invited to the Cannes Film Festival in France, as the Chinese animation recommended brand debut in the international market. In addition, the Confucius Institute Headquarters has "Confucius " series of books and audiovisual materials into designated, translated into many languages, will be the world's more than 300 Confucius Institutes and Confucius classroom all the recommendations and release. You can say that the cartoon " Confucius" achieved a huge success.

In creation, creators insist ideological, historical , artistic, interesting both in principle, based on historical data , try to strip the body of a vassal Confucius utilitarian colors, and strive to restore the original appearance of Confucius and 
true ideas, it is well realized the profound traditional culture and youth 's favorite butt anime art, and its unique Chinese style , vivid form of artistic expression and educational implied was a great success, and this success is inseparable from the design material and plot.

Creators in an interview , said: " cartoon" Confucius " is not just making a commercial or artistic production, but a reconstruction of the classic Chinese culture is in this cultural expectations ." Confucius "Once combined a variety of cultural factors, demonstrated knowledge of Chinese culture , the integration of educational philosophy, the virtues of nurturing and cartoon arts together, so we get the majority of the audience accepted and loved ."

Conn, son surname, name Qiu , styled Zhong $\mathrm{Ni}$ is animated film " Confucius ," the protagonist . He is a thinker educator and statesman, founder of Confucianism in the late Spring and Autumn Period, a representative of Confucianism . Jing two years ( Gengxu ) August 27 SHEN Shi was born in Qufu, Shandong Province . Shangqiu origin , the ancestors of the Shang Dynasty Shang founding monarch . Song after anti- tert- hole people, students Boxia , Bo Xia Shengshu beam knot . Confucius ancestor seven holes Father Kerry is in the court of civil strife in China killed Christ, the Father of his son Kim Wood Zou Yi Lu fled to take refuge in his father 's words bore me .

Animated film " Confucius" Confucius story is from the Spring and Autumn Period in which the Eastern Zhou dynasty began to tell , when the Western Zhou society with blood clan -based political system collapse collapse , and cultural identity of the Han nationality -based community is being formed. This is the era of Chinese people 's cultural consciousness initially occurred, classical fashion, some people began to think of Heaven, life and other aspects of the world order , originally dominated by the aristocracy of culture and education are also gradually flow into the private sector. It is this spirit of the times of Confucius representatives and synthesizer, then a precedent for the country philosophers of war.

The animated film " Confucius" in chronological order , showing the growth process and the formation of Confucius Confucian culture origins, focus on the performance of his distinguished from ordinary people to become thinkers , philosophers process.

To this end, cartoon academic thoughts of Confucius had some romantic creation, making it easier for the audience to understand the essence of Confucianism . So "Confucius " From an opening there are two fictional elf, an orchid plant, an animal skin off. Orchid Fairy's image, often appear in the dream of Confucius, the Confucius become confused when Ariadne, as a confidante, in fact, this is a metaphor for the character of Confucius. Meanwhile orchids as an omniscient perspective of the storyteller, often out of the question meaning and purpose to be told, to reflect thoughts and aspirations of Confucius. Lu was originally the Imperial Ancestral Temple skin off the wall auspicious animal, he who has a lot of small shortcomings, but goodness, is a typical representative of Confucius devoted his life to the transformation of human weakness. Orchid symbolizes noble character, and skin off the representative vulnerability, vanity, laziness, Confucius side, under his probation. Orchids and skin off, around the side of Confucius, Confucius 's words and deeds are often out of the debate, and indeed Confucius complex inner world of externalization. Orchid Fairy, skin off both adding and shaping the image, not only the color cartoons full of fantasy and imagination, but also more in line with children's cartoon viewers thinking and psychology.

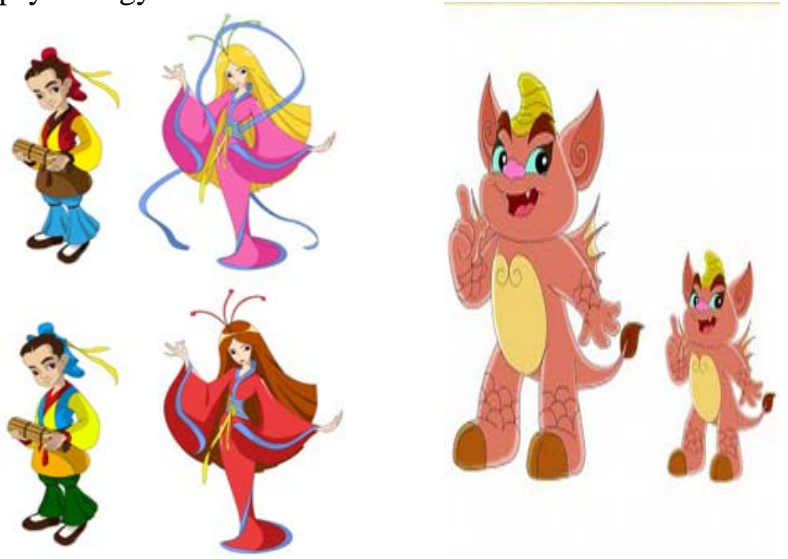

Figure 2. Orchid plant and animal skin.

\section{CONFUCIUS CREATION NARRATIVE STRUCTURE}

\section{A. Narrative structure}

In the narrative structure, "Confucius" special structure independent way once again in series, will be one independent intrinsically linked stories woven into a complete system , with elegant and simple cartoon image and ups and downs of the plot development, the audience from the " story " in comprehend truths . For example, in the " tyranny " of a set, with Zi Zhong went to shoot the tiger, let skin off as a decoy, was nearly eaten by a tiger skin off himself in the nick of time, transformed into a fire-breathing auspicious scare the tiger, rescued himself . Lippi wants to break the story to have a beautiful dress, because he thought wore good clothes, in order to become a gentleman. Then fold is not so simple, and in the " Provincial " a centralized, Confucius has a superb juvenile Yu surgery , extraordinary courage, and his friend Man Fu is a naturally shy person, but his sincerity and kindness, so he became a follower of Confucius ideal young friend and the most for the lifetime of Confucius ; here on behalf of the powerful party domineering, bullying aristocratic teenager Yang $\mathrm{Hu}$ challenge Confucius Yu surgery, want humiliated, the results of Confucius with wisdom and superb technique defeated Yang $\mathrm{Hu} \mathrm{Yu}$, won a race victory. And get the appreciation and affirmation. Such dramatic story to let the audience feel the full breath of life behind the role of Confucius. 


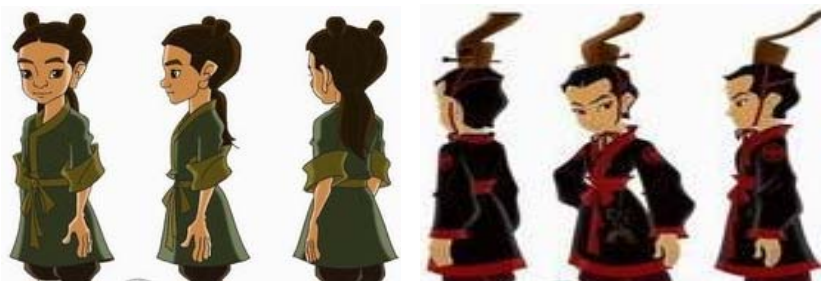

Figure 3. Man Fu and Yang Hu.

\section{B. Unique traditional culture}

Animated film " Confucius " screen clear, a few strokes on revealing the character of Confucius, the story of independent and complete, not only vividly reflects the life experiences when Confucius growth, but also to many of his posterity popular and easy ideas understand to explain out. In the movie "Confucius ", the traditional system of the Spring and Autumn Period music, ritual, there are bells, there is painting, and both Spring and Autumn Period of Chinese history reveals charm, coupled with the use of animation overall picture of ink painting texture conduct performance, then using classical Chinese music, classical spectrum system with Analects theme song, coupled with the unique Chinese myth and legend, formed a Chinese traditional culture unique artistic style.

From the aesthetic value on the art of animation, its the distinctive Chinese national style of art is very loved by the masses of the nation , acceptance, but also give the viewers to exotic ethnic Chinese-style beauty. Thus, during the time of creation of animation to emphasize the uniqueness of traditional culture, otherwise it will lose the contents of a unique charm, traditional culture of the work given the inherent attractiveness and natural affinity , is the traditional national culture planted in a country or cultural characteristics of ethnic endless psychological depths. It should be said , in order to make an animated works marked "Made in China" brand, allowing viewers to feel the distinctive style of traditional culture, we must consciously infuse fine Chinese humanistic spirit in the works.

On the whole structure, the performance of the creators of Confucius studious teenager, the fear of suffering, dutiful sense , middle-aged inspirational save the world when , in old age traveling to spread lectures. Stories in different periods , such a huge story also pay attention to the content based on the Chinese classics "The Analects" is a classic, it purifies the body 's many tributaries in Confucius utilitarian colors, and insisted the idea of the performance of the authenticity of art , giving the animated film " Confucius " and " history" of heavy precipitation and "epic" is legendary, the clever combination of the unique spirit of Confucianism and Chinese traditional culture is full of interesting ideas and animated stories. It is precisely because of this,"Wen Road ," the grand structure creators in the plot to the design and performance of the Chinese character style nationalization capability to show in it. Confucius Language troubled times, he devoted his life to pursue benevolent ideology in politics; engaged in preaching, Tuition, FAQ on education, breaking the monopoly of education, creating a private school pioneers, the people in ignorance of enlightenment, is known as the " sage teacher, teacher for all ages." Plot designed to continuously enrich the character's image, so that character becoming plump, Confucius pursuit of faith in the course of the story, the integrity of the stick , choice of friends, loyal finds have been fully revealed, integrity, Zhongxiao, integrity and morality of the Chinese mainstream, but also his life a consistent body of consciousness. Confucius Confucianism growth process is a process of continuous development and maturation, from Confucius, who embodied by the " warm, good, Christine, frugal , so, benevolence, righteousness, propriety, wisdom and trust " is the accumulation of the Chinese nation in the blood character. This " re-creation " process, that is, the strong stretches over 5,000 years of history and cultural heritage integrate into the overall framework of the story , in a sense, "Confucius ," the focus is not to pay their last respects to deliberately shape for the "Confucius" image, but also focus on about that period of history and culture, it is hoped the children through the film philosophical connotations sentiment, on spiritual purification and sublimation . Animated film " Confucius" is dedicated to young people in traditional cultures and a bridge , so that small audience through their favorite form of understanding of Confucius that was originally in the hearts of children up vivid Confucius distant, so that the original incomprehensible for children Confucianism, "benevolence " spirit gradually penetrated into the children's lives, feel the idea of the resurrection of Confucius in modern society, to appreciate Confucius personal charm.

Pan Lusheng Shandong Academy of Fine Arts Dean said: "Confucius".The combination of tradition and entertainment, from the most simple and intuitive for kids to classical culture imprint, the promotion of traditional culture, communication and 'going out' with a profound sense. " In the economic globalization, cultural same trend, maintaining national consciousness, national characteristics, is particularly important. As an effective means to relive the Confucian classics, to promote the spirit of Chinese culture, the role of the animation is obvious. Both young people about the history of the fun of watching the movie, but also to learn Analects knowledge, yardsticks, naturally form a cultural sense of belonging, so let the youngsters grew gradually form a national literacy , and this national literacy gradually accumulate, will form the entire nation temperament. So we from the animated film " Confucius ," the hit can be seen because of its subject matter in mind and has a wealth of historical and cultural connotation of the spirit, but also because it can be well satisfied with the traditional thinking of the people now on the domestic cartoon and the pursuit of knowledge beyond .

\section{CONCLUSION}

Animated film "Confucius" about the way plain , traditional culture among the sounds of storytelling is showing . By about the rough life of Confucius and his educational experiences influence others, the core values of Confucius "benevolence" stand up , the traditional virtues of the Chinese nation, "Wen , Liang, Christine , thrifty, so 
that" sow the thought of young children consciousness, so that the film is a lot of Confucius 's famous aphorism children naturally understand, clear in mind . It is in this cultural expectations , "Confucius" combines a variety of cultural factors, demonstrated knowledge of Chinese culture , the integration of educational philosophy, the virtues of education and the arts combine animation, has been accepted and loved by the audience. Animated film " Confucius" cultural sustenance expect a lot of the audience, also in line with the current mainstream cultural values , and the trend of the times to adapt. China Confucius Foundation chairman Liang Guodian , the " cartoon 枟 Confucius Zui stick in the creative process of ideological principles, authenticity, artistic, interesting both as to the basis of historical data , try to strip him of many vassal Confucius utilitarian color , and strive to restore the original appearance of Confucius and true ideas . " It can be said , "Confucius" take advantage of this form of public loved the animation , especially the young people most likely to accept the storytelling, the knowledge , the truth and the fate of the characters closer together through this special character of Confucius, only with animation Interpretation of forms of traditional culture is a new exciting show in the history of advancing the development of domestic animation , it also brings new inspiration for the future of the domestic animation .

List and number all bibliographical references in 9-point Times, single-spaced, at the end of your paper. When referenced in the text, enclose the citation number in square brackets, for example [1]. Where appropriate, include the name(s) of editors of referenced books. The template will number citations consecutively within brackets [1]. The sentence punctuation follows the bracket [2]. Refer simply to the reference number, as in [3]— do not use "Ref. [3]" or "reference [3]" except at the beginning of a sentence: "Reference [3] was the first..."

Number footnotes separately in superscripts. Place the actual footnote at the bottom of the column in which it was cited. Do not put footnotes in the reference list. Use letters for table footnotes.

Unless there are six authors or more give all authors' names; do not use "et al.". Papers that have not been published, even if they have been submitted for publication, should be cited as "unpublished" [4]. Papers that have been accepted for publication should be cited as "in press" [5]. Capitalize only the first word in a paper title, except for proper nouns and element symbols.

For papers published in translation journals, please give the English citation first, followed by the original foreignlanguage citation [6].

\section{REFERENCES}

[1] Zhou Xian, "Visual culture : from traditional to modern," Wu Limin. Trans. Beijing, vol. 184, pp. 131-140, June 2007.

[2] LIU Ying, "The translation course of Confucius doctrine in Russia," Confucius Studies, 2010, pp . 319-324.

[3] CHANG Shengyan, "Demoning image in traditional China and the shaping of villains in animation," Confucius Studies, 2007, pp . 171178.

[4] WU Wensheng, "Fingarette Confucius: The Secular as Sacred,”. Nanjing: Jiangsu People's Publishing House, 1963, pp. 271-350.

[5] FAN Wei, "Louth light New History of Chinese Philosophy," unpublished. Nanning : Guangxi Normal University Press, 2011, pp .45-51.

[6] D. Kornack and P. Rakic, "Cell Proliferation without Neurogenesis in Adult Primate Neocortex,” Science, vol. 294, Dec. 2001, pp. 21272130, doi:10.1126/science.1065467. 